\title{
The impact of local variations in a temperate maritime climate on
}

building energy use

Ralph Evins $^{\mathrm{a} *}$, Ross Alexandra ${ }^{\mathrm{b}}$, Ed Wiebe $^{\mathrm{c}}$, Michael Wood ${ }^{\mathrm{d}}$ and Matthew Eames ${ }^{\mathrm{d}}$

${ }^{a}$ Department of Civil Engineering, University of Victoria, Victoria, BC, Canada;

${ }^{b}$ Department of Computer Science, University of Victoria, Victoria, BC, Canada;

${ }^{c}$ School of Earth \& Ocean Sciences, University of Victoria, Victoria, BC, Canada;

${ }^{d}$ College of Engineering, Mathematics and Physical Sciences, University of Exeter, Exeter, UK.

*revins@uvic.ca 


\section{The impact of local variations in a temperate maritime climate on building energy use}

We investigate the impact of local climatic variations on the energy performance of buildings by conducting simulations using weather files generated from high-resolution weather measurements covering 33 stations within a $77 \mathrm{~km} 2$ area in southern Vancouver Island, British Columbia, Canada. Weather files were created by resampling and cleaning the data and applying appropriate models to obtain unmeasured values. The difference in microclimate has been analysed statistically and graphically; average annual temperature varies by around $1{ }^{\circ} \mathrm{C}$, and at certain times there is a $6^{\circ} \mathrm{C}$ variation across the (very small) region.

Building energy simulations of a small naturally-ventilated office building and a larger air-conditioned building were performed using EnergyPlus for all weather files. Significant variation is found spatially and temporally which would have substantial implications for building design and energy use. The variation in annual heating energy use is $+/-5 \%$ of the mean, equivalent to $18 \mathrm{kWh} / \mathrm{m}^{2} / \mathrm{a}$, with even greater relative variation in cooling energy use.

Keywords: microclimate; weather; building energy use 


\section{Introduction}

\subsection{Background on weather data and building simulation}

Design weather data is typically used in building performance simulation to determine how a building design might perform once built. Typical weather files such as a Test Reference Year (Eames, Ramallo-Gonzalez and Wood 2016) or a Typical Meteorological Year (Wilcox, S and Marion, W 2008) are used to see how a building might behave on average. Alternatively weather files containing near extreme events (Eames 2016) can be used to stress test a building. Such weather files contain hourly data on temperature, solar irradiation, humidity, and wind direction and wind speed. These files are typically compiled from observations which range from 10 to 30 years from a specific location (Herrera et al 2017).

There are limitations in the use of weather data from observations, foremost among which is that observations are only sparsely available worldwide, reducing the applicability of the weather data to the building site. For example in the city of Victoria, Canada, the $\mathrm{CWEC}^{1}$ weather file typically used for building performance simulation is based at Victoria International Airport, $25 \mathrm{~km}$ to the north. The weather file is then used for buildings which are located in the suburbs, urban areas and on the coast equally. Further guidance would then be required if any adjustments are needed, which is not often available. As a result the weather files are nearly always used as if the building is located at the weather station. This situation is not unusual worldwide. In the UK design weather years are available for compliance modelling at only 14 locations (Eames, Ramallo-

\footnotetext{
${ }^{1}$ Canadian Weather for Energy Calculations (CWEC) weather data uses a methodology similar to TMY2 data. See (Numerical Logics 1999).
} 
Gonzalez and Wood 2016). Scotland is serviced by only two weather files; one for Edinburgh and one for Glasgow. This in effect splits Scotland in half and locations far from the two cities are considered comparable.

The internal environment is highly dependent on the external environment, which forms the major boundary condition for all building energy simulations (Coley and Kershaw, 2010). Local microclimatic variations can have a significant impact on the performance and energy use of buildings. It has been shown that neighbouring buildings affect the convective and radiative heat transfer in urban areas, which in turn impacts the heating and cooling demands (Allegrini, Dorer, and Carmeliet 2012). It has also been shown that the configuration of buildings (the urban morphology) affects the local microclimate, which manifests as increased temperatures in urban areas (the urban heat island affect) (Allegrini, Dorer, and Carmeliet 2015).

Much prior work has focussed on modelling the impact of very local urban morphology on local climate; some studies have extended this to consider subsequent impact on building energy use. Dorer et al. (2013) coupled computational fluid dynamics (CFD) models with building energy simulations, both by determining convective heat transfer coefficients and by direct coupling. Evins et al. (2014) used statistical model-fitting to apply coefficients determined with CFD in a building energy simulation. These studies can account for the impact of microclimate on the scale of a 'street canyon' between rows of buildings, or across a small neighbourhood of buildings. However, it is likely that greater errors are introduced due to larger features such as topology, urban areas and coastlines on the order of kilometres rather than meters, which make the use of source data from many kilometres away highly inaccurate.

High resolution temperature data has been used to determine the extent of the urban heat island around major conurbations. The work of Levermore established the magnitude of 
the heat island in Manchester using a set of urban through to semi-rural locations (Levermore et. al 2014). A significant urban heat island were found with a maximum mean daily value of $6^{\circ} \mathrm{C}$ which would have significant impact on HVAC design. Demanuele et al investigated the effect of the urban heat island of London on the potential of overheating in urban buildings (Demanuele, Mavrogianni, Davies, 2011). Temperatures were taken from measurements from 26 sites in an East-West transect through the centre of London. However, there were no measurements of any other weather variables at the same resolution, so these had to be taken from 'local' weather stations (Heathrow and London Weather centre). The variation of these variables across the width of the city was assumed to be small (which we show to be incorrect in our case study), so temperature alone was considered to give a good approximation for the microclimate at each location. Even with this assumption, significant changes in overheating were found, driven by the temperature measurements.

The effect of spatial resolution of weather data on the thermal performance of buildings was previously investigated using a stochastic weather generator as the source of all weather data (Eames, Kershaw and Coley, 2012). This work showed that higher resolution weather files could be of benefit to the industry and specifically that care is required when drawing up design solutions for locations far from a weather station. However, while the weather generator used in the study had a resolution of $5 \mathrm{~km}$, this was still limited by the observations used to calibrate it. All weather statistics were derived from 115 weather stations and interpolated on to a $5 \times 5 \mathrm{~km}$ grid considering the elevation, aspect, urbanisation and distance from the coast (Perry and Hollis, 2005). Locations far from the original observation locations are therefore likely to have higher uncertainty. Various studies have assessed the impact of climate variations between disparate locations on the predicted energy consumption of buildings. Hong et al (Hong, Chang, 
and Lin 2013) investigated the impact of peak electricity demand and energy use of buildings using 30 years of observed weather data from 17 climates covering all ASHRAE climate zones. The variation in the inter-annual energy use is small across all locations (around 5\%). However, the average energy use could vary by up to $40 \%$ across all locations. Crawley (Crawley 1998) investigated the impact of weather on energy use for an office building from using 30 years of data for eight locations covering a range of climates in the US. Locations which are require significant space conditioning had a high inter-annual variation in energy use although the overall inter-annual variability was small with the minimum energy use $11 \%$ smaller than the average and the maximum only $7 \%$ bigger. However the annual energy consumption in Minneapolis was $163 \%$ higher than in Los Angeles. In this case the climate was a significant driver of not only the overall energy use but the mechanism for the energy use. Bhandari et al. (Bhandari, Shrestha, and New 2012) compared the weather characteristics at a building site with data collected from nearby weather stations and the impact on energy use in three test buildings. The observed temperature was found to differ up to $17 \mathrm{C}$ across the weather sets. The overall energy use varied by up to $7 \%$ depending on the weather data used but cooling and heating loads could differ by up to $40 \%$ when using the different weather datasets.

In this paper we explicitly consider variations in high spatial resolution measured weather data and its implication on the built environment for the first time. As building simulation moves towards accurate performance prediction rather than compliance with standards, it becomes more important to account for such critical variations in the primary boundary condition of the simulation. 


\subsection{Weather measurements with high spatial resolution}

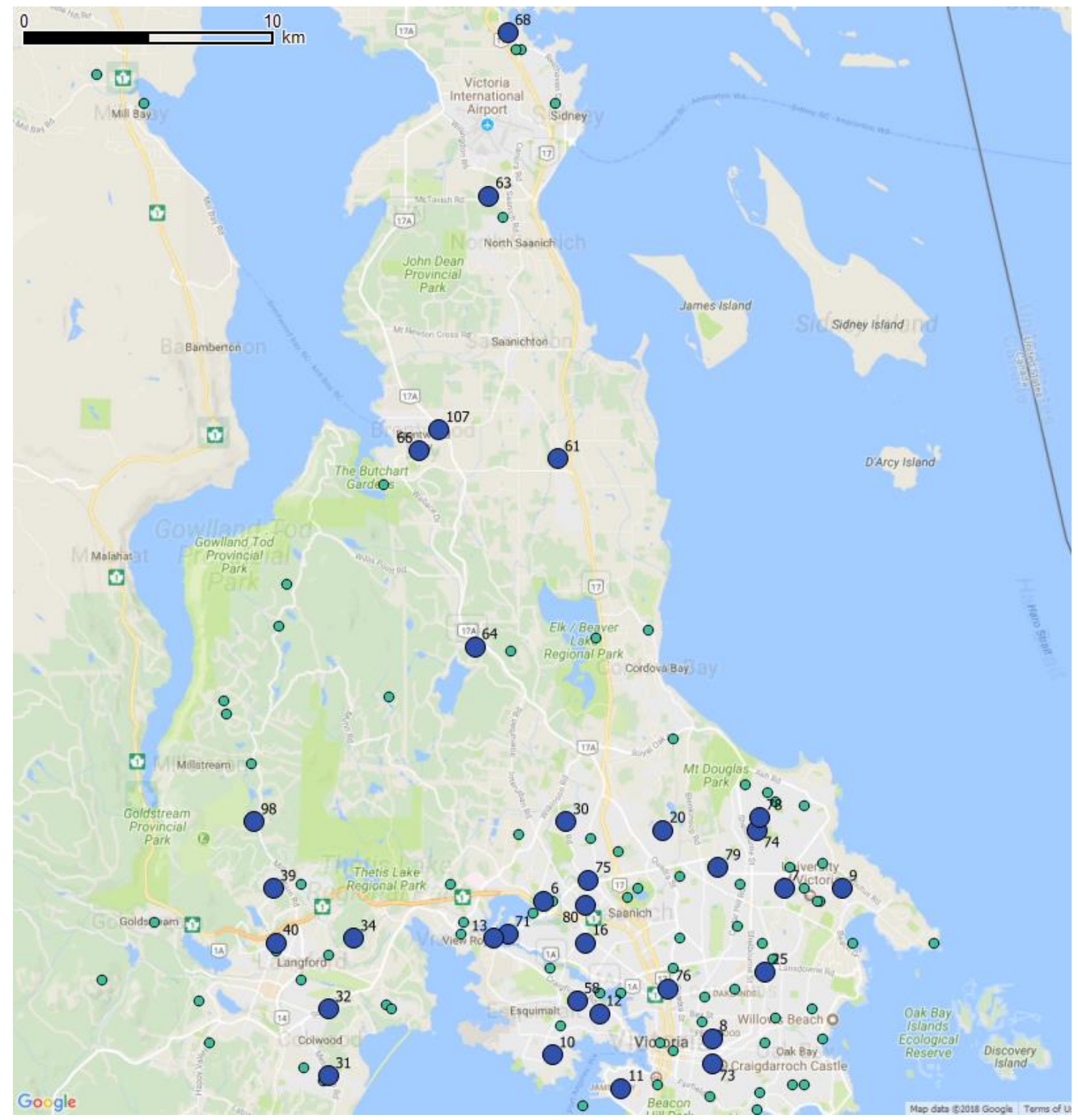

Figure 1: The locations of the 33 School-Based Weather Station Network stations near Victoria used in this study (blue circles with ID numbers as referred to in the text), and the other unused stations (small green circles). The inset shows the location of Victoria on the west coast of Canada.

The School-Based Weather Station Network ${ }^{2}$ is a collection of weather stations on Vancouver Island in British Columbia, Canada. The network gathers, processes and

${ }^{2}$ http://www.victoriaweather.ca/ 
displays data for educational purposes, and provides interactive, localised resources for the K-12 (age 4 to 17) science and mathematics curricula. Twenty stations were installed in 2005 , rising to 79 in the Greater Victoria area by 2017. Each weather station measures atmospheric temperature, atmospheric humidity, UV Index, incoming solar radiation, wind speed, wind direction and atmospheric pressure (corrected to sea level). The data is recorded at 1 minute intervals and sent to an SQL database on a central server.

This work focusses on a set of stations clustered around the City of Victoria, as shown in Figure 1. Of the 79 stations in this region, 33 were selected as having reasonably high quality data recordings (see Methodology step 2). The peninsular is roughly $32 \mathrm{~km}$ by $10 \mathrm{~km}$, with a land area of around $250 \mathrm{~km}^{2}$; the urban cluster of Victoria in which 26 of the stations are located is around $12 \mathrm{~km}$ in diameter, with a land area of about $77 \mathrm{~km}^{2}$. This resource provides very high spatial resolution weather data, with an average one station per $7.5 \mathrm{~km}^{2}$, rising to one per $3 \mathrm{~km}^{2}$ for the urban cluster. This resolution is greater than the synthetic weather study of Eames et al (2012), which interpolated to give one data point for every $25 \mathrm{~km}^{2}$.

An example of typical siting of the weather stations used in this study is shown in Figure 2, showing the weather station installed on the roof of a school building, and Figure 3, showing that although there are buildings and trees in the vicinity of the station, there is no direct shading or sheltering of the sensors. To the best of our knowledge all sensors are installed on the roof of a main school building, which is typically bordered by playing fields and car parks, minimising the risk of direct shading or sheltering.

It should also be noted that because the purpose of the study is to assess the climate conditions experienced at the exact building locations, if there is minor shading (e.g. of a small portion of the sky dome) or minor sheltering (e.g. slight redirection or slowing of wind from a certain direction), including these effects in the study gives a better picture 
of the conditions actually experienced by the building elements.

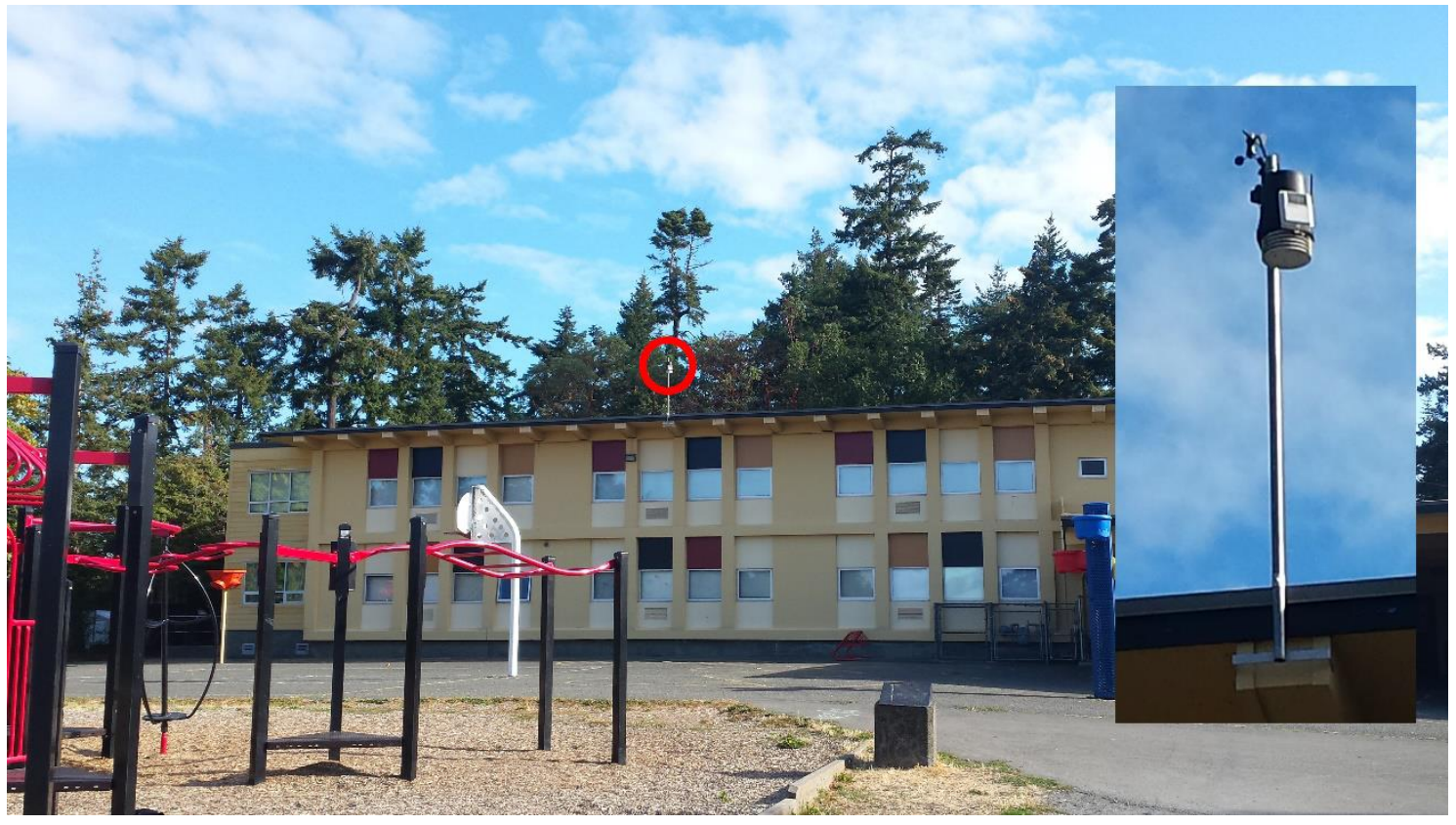

Figure 2: Photograph looking North-East at Station 71 (highlighted with a red circle). The inset shows a close-up of the mounting of the weather station on a pole approximately $1.5 \mathrm{~m}$ above the roof.
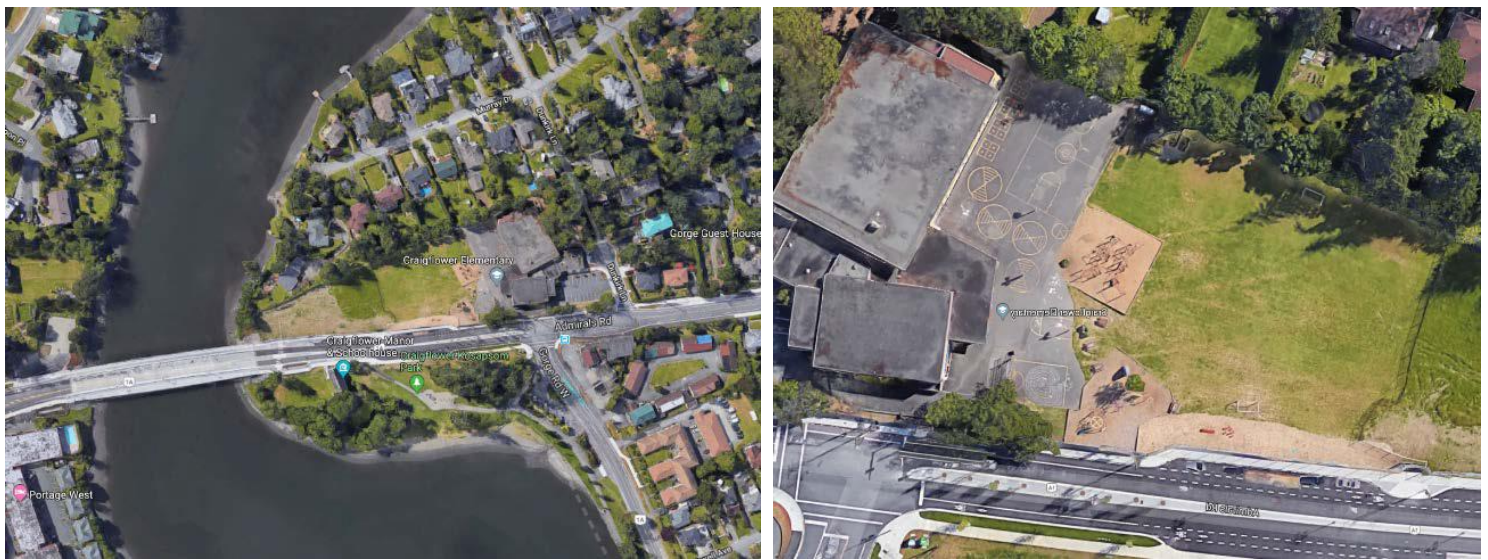

Figure 3: Large-scale satellite images of the location of Station 71 (red circles), with approximate scale bar bottom right in both images.

\subsection{Outline of this paper}

The weather station network in Victoria makes an excellent resource for the investigation of building energy use variations across the region. This work takes the weather data with 
very high spatial resolution and investigates the resulting variations in simulated building energy performance. We first present the methodology used, including data extraction and processing, the accuracy of the measurements, steps taken to generate parameters that were not measured, the methods of analysis of variations in the weather data generated, and the case studies for which building simulations were performed for all weather files. This is followed by the results and a discussion of their meaning for the observed microclimatic variations and the changes in predicted energy use. Finally we draw conclusions from these findings regarding the impact of microclimate variations on building design and possible avenues for future investigation.

\section{Methodology}

The overall methodology employed in this work is as follow:

1. Values are extracted from the SQL database of weather station records for each station for the first minute of every hour for the period of interest. For this work we examine the year 2012, as it has the most complete record.

2. The dataset is cleaned to account for missing values. This follows the steps below:

- All stations with more than 10\% missing values are discarded, and all stations with more than 24 sequential hours of missing data across all parameters are discarded. Due to the non-professional nature of the stations and associated data gathering infrastructure, this reduces the number of stations from 79 to 33, however this is necessary in order to retain a reasonable degree of robustness in the analysis of the weather data.

- Remaining sections of missing data are labelled as missing for use in EnergyPlus (step 5). 
- Remaining sections where data is missing for a whole 24 hour period are labelled as missing for calculating daily averages (step 4).

- Remaining sections where data is missing for less than a 24 hour period are calculated as daily averages over the values present (step 4).

3. Additional parameters needed for the simulation that were not recorded at the weather stations are determined using the methods outlined in the following section.

4. Statistical and graphical weather data analysis is performed by comparing each of the weather files generated to the mean across all stations for that hour.

5. Weather data for each station is exported in EnergyPlus Weather File (.epw) format.

6. Building energy simulations are conducted as detailed below for a reference design using each of the weather files generated, and the results compared to those obtained with the standard Canadian Weather for Energy Calculations (CWEC) ${ }^{3}$ weather file ${ }^{4}$ for Victoria airport.

\subsection{Accuracy of recorded data}

The weather stations used in the Victoria Schools Weather Network are Davis Vantage Pro 2s, a 'high-end amateur' station that retails at \$650US. The sensor accuracy is $+/-0.3 \mathrm{C}$, with a maximum radiation induced error of $2 \mathrm{C}$. Station siting is ad hoc, typically on rooftops, at the edges or corners of structures. Siting decisions were made

\footnotetext{
${ }^{3}$ https://energyplus.net/weather/sources\#CWEC

${ }^{4}$ https://energyplus.net/weatherlocation/north_and_central_america_wmo_region_4/CAN/BC/CAN_BC_Victoria.717990_ CWEC
} 
for safety and convenience of access, separation from building exhaust systems, reduced risk of vandalism, and finally consideration of meteorological value. Each site is different due to building shape and its position with respect to topography, other structures, trees, and so on. No corrections are applied to the wind data. As shown in Figure 2, siting is typically on a pole above a roof of a main school building.

Because the stations are not professional quality and are not ideally sited, this may introduce a source of error into the analysis conducted here. Formally, the temperature difference $T_{\text {diff }}$ (for example) is described using the equation below, where $T_{1}$ and $T_{2}$ are the real temperatures at two stations, and $\varepsilon_{1}$ and $\varepsilon_{2}$ are the measurement errors at the two stations.

$$
\mathrm{T}_{\mathrm{diff}}=\left(\mathrm{T}_{1}+\varepsilon_{1}\right)-\left(\mathrm{T}_{2}+\varepsilon_{2}\right)
$$

We assume that even though the stations are not ideally sited, any errors introduced are relatively equal, such that they cancel out in the expression above. In the analysis and discussion, we are (largely) making the assumption that $\varepsilon \ll \mathrm{T}$ when looking at the distribution of the temperature differences. It is also worth noting that $\varepsilon$ will likely be very different for different variables, for example for wind speed and direction measurement errors could easily be much larger than those for temperature.

Whilst it will not be universally true that $\varepsilon \ll \mathrm{T}$, and it is possible that error terms act in opposite directions thus exacerbating rather than cancelling each other, the data quality is reasonable assumption for the purposes of the annual statistical analysis of variations that forms the main contribution of this work.

This is corroborated by the data in Figure, which shows that there is no systematic bias between the Davis Vantage Pro 2 station at the University of Victoria and the 
Environment and Climate Change Canada station on the other side of campus, $1.8 \mathrm{~km}$ away across relatively even topology at a very similar elevation and aspect. It is not possible to perform a more detailed comparison, as there are variations because the two stations are not co-located. Therefore, some caution should be exercised when analysing the data in detail, for example at specific times of day, as there may be uneven errors that skew the results. Whilst there are stations in the school weather network that are more closely located that this for which significant differences can be observed, it is reasonable to attribute this to topographical variations rather than instrument error. The point of the comparison is to demonstrate that the station reports values that are similar enough to professional equipment nearby to be useful. Whilst some sources of error undoubtedly remain, the dense network of stations across an area of great topographical diversity provides useful information for a high-level statistical analysis.

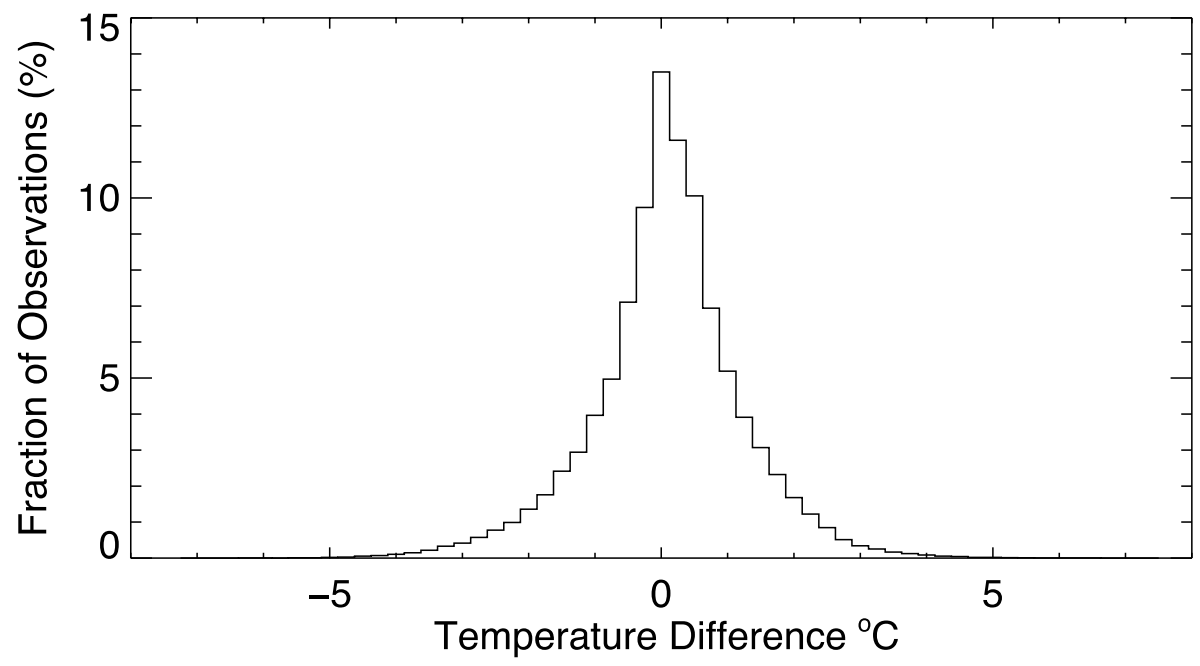

Figure 4: The distribution of differences between 110,000 hours of data (2002 to 2015) from the Davis Vantage Pro 2 station at the University of Victoria and the Environment and Climate Change Canada station 1.8km away.

\subsection{Generating additional values required}

The key values required for building energy simulation that are not present in the measured data are: 
- Dew point temperature

- Direct beam solar radiation and diffuse horizontal radiation

- Illuminance

The following sections outline the process used in each case.

\subsubsection{Dew point temperature}

The dew point temperature is a required variable in EPW weather files and as an input for the illuminance calculations. The observed weather data contains the dry bulb temperature and the relative humidity. The dew point temperature can be therefore estimated directly from psychrometric formulas (ASHRAE Fundamentals, 2017). The dew point temperature is the point at which the air temperature must be lowered to become $100 \%$ saturated with water vapour. The dew point temperature is solved iteratively.

\subsubsection{Solar radiation}

The observations contain the global horizontal radiation but for modelling solar radiation through windows and for illuminance calculations, the direct and diffuse solar radiation components are required and thus must be estimated here. There are a number of approaches to calculate solar radiation where no measurements exist. These include empirical models which take into account the weather in previous hours (Huang, 2014), and analytic models (Muneer, Gul, Kambezidis, 1997) using meteorological data.

Ideally long term cloud cover data would be used to differentiate between the direct and diffuse components. However such cloud cover data is not available at the same resolution as the rest of the observations. Satellite data is a possible source of cloud cover 
data, however high spatial resolution data is only available at 12 hour intervals, and low spatial resolution data at 15 minute intervals is not available for the time periods covered by the observations. The approach taken here is to consider the cloud cover from the airport as representative for the entire area. The extracted cloud cover ( $\mathrm{CC}, 0$ to 8 scale) is then converted to the sunshine fraction (SF) using the simple formula below.

$$
S F=1-C C / 8
$$

The solar duration in an hour depends on the solar altitude and the cloud cover. For the diffuse and direct components the MRM model is used (Psiloglou, and Kambezidis, 2007). The MRM model is a simple model which takes air temperature, relative humidity, barometric pressure and solar duration as an input. The key meteorological variables are recorded at all locations. The MRM model is calculated using the standard approach but at each location and hour the global solar radiation observation is used as an input rather than being calculated.

The MRM model has been shown to have a Root Mean Squared Error of around 20W/m2 when compared to measured data (Psiloglou, and Kambezidis 2007). Regarding the impact of the accuracy on the energy use of buildings, Neto and Firelli (2008) found that an uncertainty of $+/-20 \mathrm{~W} / \mathrm{m} 2$ in solar radiation equated to a variation of $+/-1.2 \%$ in building energy consumption.

\subsubsection{Illuminance}

Lighting energy calculations require illuminance data at the same temporal resolution of the underlying weather data. Hourly values of global horizontal illuminance, diffuse horizontal illuminance, and direct normal illuminance are calculated using models developed by Perez (Perez et al, 1990). These models take the solar altitude, global horizontal radiation, diffuse horizontal radiation, dew point temperature and extra- 
terrestrial horizontal radiation as an input.

\subsection{Analysis of microclimate variations}

To analyse the variations in local microclimate between the stations, the following steps were conducted:

- Calculate the mean, minimum and maximum daily dry bulb temperature $\left(\mathrm{DB},{ }^{\circ} \mathrm{C}\right)$, relative humidity $(\mathrm{RH}, \%)$, global horizontal solar radiation $\left(\mathrm{SR}, \mathrm{W} / \mathrm{m}^{2}\right)$ and wind speed (WS, m/s) for each day of the year for all stations.

- Calculate the daily average DB, RH, SR and WS for all stations.

- Investigate trends in DB, RH, SR and WS by examining the deviation between each station and the average over all the stations.

Spatial correlations were analysed using the following steps:

- Calculate the distance matrix between all pairs of stations.

- For DB, RH, SR and WS, calculate the correlation coefficient between the annual hourly time series data for all pairs of stations.

- Examine the relationship between distance and time series correlation across the set of all stations.

\subsection{Building energy simulations}

Building energy simulations have been conducted for two reference buildings using EnergyPlus, representing a naturally-ventilated office case (NV) and an air-conditioned office case (AC). The buildings are shown in Figure 5, and properties are summarized in table 1. This will uncover the impact of local climate on heating loads (both), and cooling loads (AC). 
(a)

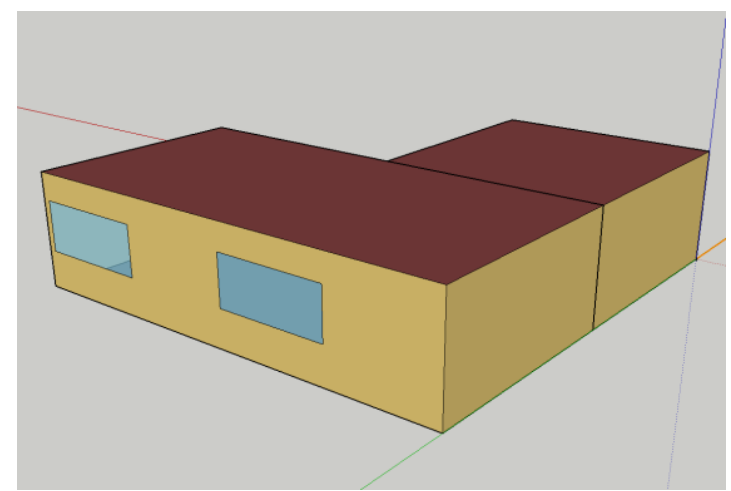

(b)

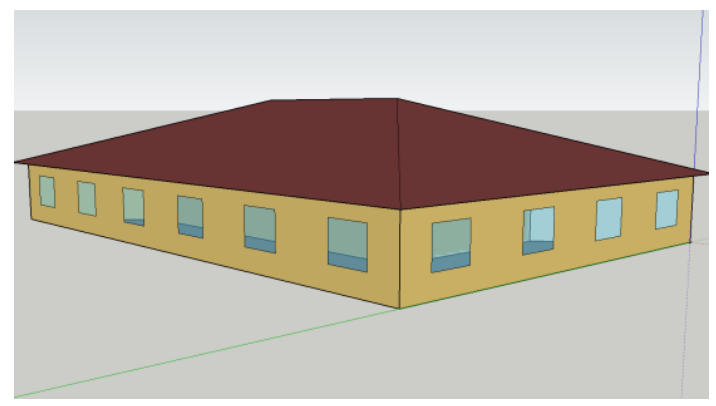

Figure 5: Naturally-ventilated (a) and air-conditioned (b) case building models.

Table 1: Properties of the two case study buildings.

\begin{tabular}{|l|c|c|}
\hline & Naturally-ventilated case & Air-conditioned case \\
\hline Area $\left(\mathrm{m}^{2}\right)$ & 111 & 512 \\
\hline Wall U value $\left(\mathrm{W} / \mathrm{m}^{2} \mathrm{~K}\right)$ & 0.17 & 0.17 \\
\hline Roof U value $\left(\mathrm{W} / \mathrm{m}^{2} \mathrm{~K}\right)$ & 0.17 & 0.17 \\
\hline Floor $\mathrm{U}$ value $\left(\mathrm{W} / \mathrm{m}^{2} \mathrm{~K}\right)$ & 0.17 & 3.2 \\
\hline Window $\mathrm{U}$ value $\left(\mathrm{W} / \mathrm{m}^{2} \mathrm{~K}\right)$ & 5.9 & 10.7 \\
\hline Equipment $\left(\mathrm{W} / \mathrm{m}^{2}\right)$ & 52 & 10.7 \\
\hline Lighting $\left(\mathrm{W} / \mathrm{m}^{2}\right)$ & 5 & 28 \\
\hline Occupancy $(\mathrm{people})$ & 7 & \\
\hline
\end{tabular}

\subsubsection{Naturally-ventilated (NV) case}

The naturally-ventilated case is based around the 'AirflowNetwork3zVentAutoWPC.idf' example file provided with EnergyPlus, to allow the study to be easily replicated using publicly available models. This represents a small office building with natural ventilation modelled using an Air Flow Network (Gu 2007), 
and is typical of the North American building practices found in Victoria. The envelope thermal properties are: walls and roof $0.167 \mathrm{~W} / \mathrm{m}^{2} \mathrm{~K}$, windows $5.9 \mathrm{~W} / \mathrm{m}^{2} \mathrm{~K}$. The building is shown in Figure (a). The following changes have been made to the example file.

- The location object was removed as this is given in the weather files generated.

- The run period was changed to 8760 hours.

- An Ideal Air Loads system was added, with heating set points of $21^{\circ} \mathrm{C}$ from $8 \mathrm{am}$ to $6 \mathrm{pm}$ on weekdays and $12^{\circ} \mathrm{C}$ otherwise, and no cooling.

- The East zone (which has no ventilation) was removed, and the construction of the remaining walls changed to exterior. The total building area was therefore $111 \mathrm{~m}^{2}$.

- The building was rotated so that the main zone faces South.

- A second identical window was added to the main zone, giving a total of $8 \mathrm{~m}^{2}$ south-facing glazing and $6 \mathrm{~m}^{2}$ north-facing glazing.

- The set point at which windows open was changed to $23^{\circ} \mathrm{C}$ outdoor air temperature, and closing at $50^{\circ} \mathrm{C}$.

- Lighting was added to the West zone, and lighting loads for all zones changed to $5 \mathrm{~W} / \mathrm{m}^{2}$

\subsubsection{Air-conditioned (AC) case}

The air-conditioned case is based around the U.S. Department of Energy Commercial Reference Building for a newly-constructed small office for the Victoria climate zone $4 \mathrm{C}^{5}$. The envelope thermal properties are: walls and roof $0.167 \mathrm{~W} / \mathrm{m} 2 \mathrm{~K}$, windows $3.2 \mathrm{~W} / \mathrm{m}^{2} \mathrm{~K}$. This is provided from the above link as the file

\footnotetext{
${ }^{5}$ https://www.energy.gov/eere/buildings/commercial-reference-buildings
} 
'RefBldgSmallOfficeNew2004_v1.4_7.2_4C_USA_WA_SEATTLE.idf', which was transitioned to version 8.8 .0 of EnergyPlus. The building has an area of $511 \mathrm{~m}^{2}$, with $11 \mathrm{~m}^{2}$ of glazing facing East and West and $17 \mathrm{~m}^{2}$ of glazing facing North and South. The building is shown in Figure (b).

\section{Results and discussion of microclimate variations}

\subsection{Distributions of microclimate variations}
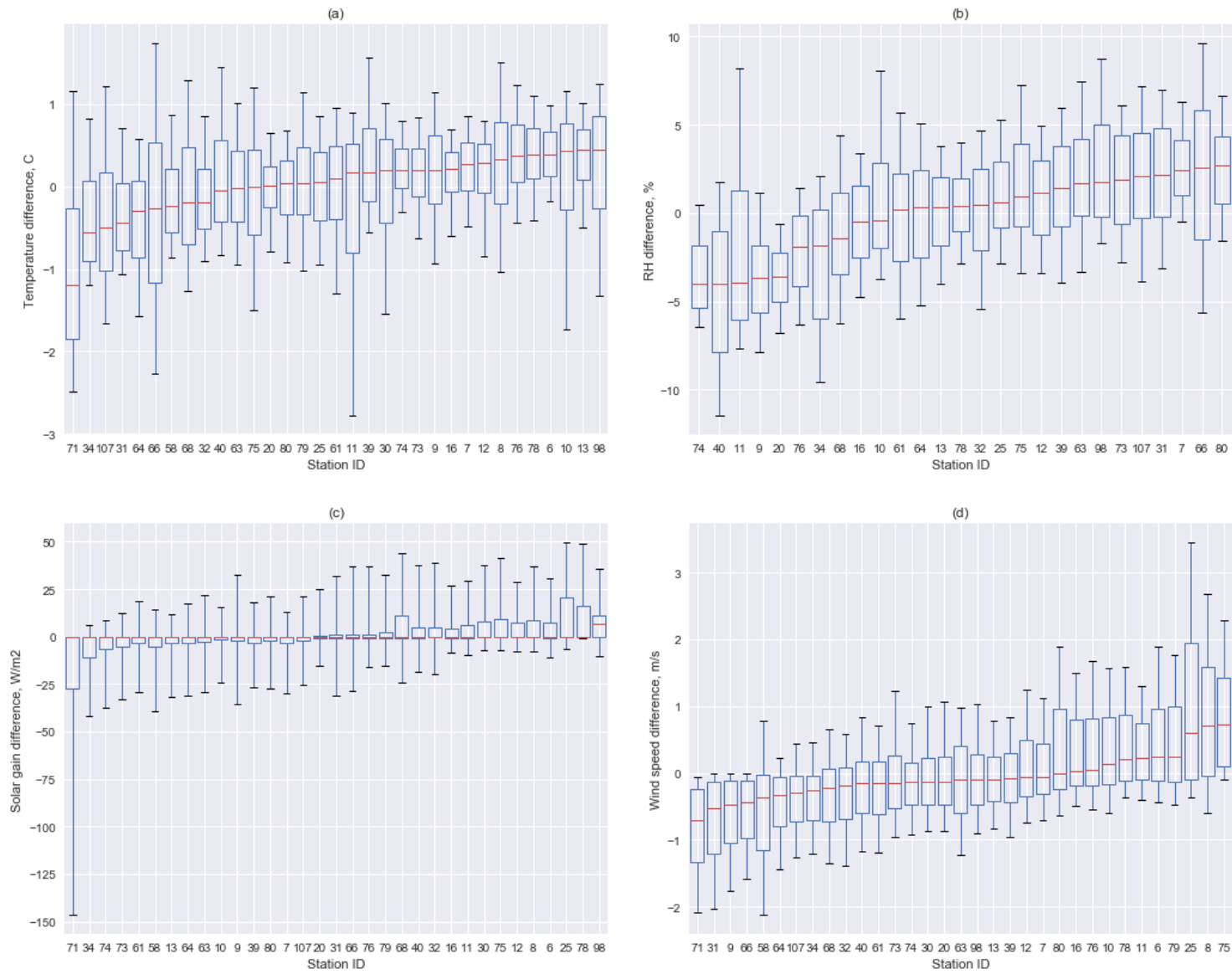

Figure 6: Box and whisker plots indicating the spread across the different stations away from the mean over all stations, for (a) dry bulb temperature, ${ }^{\circ} \mathrm{C},(\mathrm{b})$ relative humidity, $\%$, (c) global horizontal radiation, $\mathrm{W} / \mathrm{m}^{2}$ and (d) wind speed, $\mathrm{m} / \mathrm{s}$, sorted by the median deviation (red line). Boxes indicate the interquartile range and whiskers indicate the $10^{\text {th }}$ to $90^{\text {th }}$ percentile.

Figure shows how far the measurements at the different stations range away from the 
mean value across all stations, for temperature, relative humidity, solar radiation and wind speed. The 'coldest' station ( 71 , far left) is on average $-1.2^{\circ} \mathrm{C}$ below the mean, though most are within $-0.5^{\circ} \mathrm{C}$ of the mean, while the 'warmest' $\left(98\right.$, far right) is $+0.4^{\circ} \mathrm{C}$ above the mean. The boxes indicate the interquartile range, and whiskers on the boxplot indicate the $10^{\text {th }}$ to $90^{\text {th }}$ percentile ${ }^{6}$. The lowest $25 \%$ quartile (station 71 again) is $-1.8^{\circ} \mathrm{C}$ while the lowest whisker (station 11 ) is $-2.7^{\circ} \mathrm{C}$. The highest $75 \%$ quartile (98) is $+0.8^{\circ} \mathrm{C}$, while the highest whisker (66) is $1.7^{\circ} \mathrm{C}$. The longest box (indicating greatest spread of values away from the mean across $50 \%$ of a station dataset) is $1.7^{\circ} \mathrm{C}$, and the longest whisker (indicating greatest spread across $90 \%$ of a station dataset) is $4^{\circ} \mathrm{C}$.

It is notable that there is no distinct trend for 'cooler' and 'warmer' stations, with many stations that have median values below the mean station also having significant portions of hours above the mean, and vice versa. There are many stations with very large ranges, deviating significantly from the mean values over both the interquartile range and the $10^{\text {th }}$ to $90^{\text {th }}$ percentile range. More than half the stations have an average temperature more than $0.25^{\circ} \mathrm{C}$ away from the mean, a significant deviation that will impact annual energy use.

Similar trends are visible for the other weather parameters. Relative humidity lies between around $10 \%$ above and below the mean value. Wind speed varies between around $1 \mathrm{~m} / \mathrm{s}$ above and below the mean. For these variables there is a more notable trend between either end of the scale, with boxes and whiskers of broadly similar heights

\footnotetext{
${ }^{6}$ Minimum and maximum values are not shown as outlines, as these typically correspond to missing or stuck data values that give incorrect large deviations. The use of the $10^{\text {th }}$ and $90^{\text {th }}$ quartiles is appropriate because all datasets have no more than $10 \%$ missing data.
} 
following the median trend from low to high, in contrast with the higher variability in temperature.

Global horizontal solar gain varies far more dramatically, with the $10^{\text {th }}$ to $90^{\text {th }}$ percentiles for many stations reaching over $25 \mathrm{~W} / \mathrm{m}^{2}$ above or below the mean value. For all stations the maximum and minimum values for deviation from the mean reach far from the mean: the least extreme are $400 \mathrm{~W} / \mathrm{m}^{2}$, with an average of $600 \mathrm{~W} / \mathrm{m}^{2}$. It is clear that solar gain is highly erratic, due to its link with cloud cover, hence giving very different readings at the same instant. One station (71) has a lower whisker at $-150 \mathrm{~W} / \mathrm{m}^{2}$, indicating that $10 \%$ of the data is this far or further below the mean. There is no obvious error in the recorded data, though there is much greater sensitivity in the siting of instruments than for other parameters; the most likely explanation is shading of the sensor.

Solar gain differences are quite small on average, which indicates that there is little variation over a large area on average but at a given hour the difference can be high (within the limitations of the measurements). This is a potential problem for certain building energy simulation purposes - for example for overheating assessments the coincidence of slightly higher solar radiation with hotter temperatures could cause the difference between going over a threshold or not.

\begin{tabular}{c|c|c|c} 
& Temperature & RH & Solar \\
\hline RH & -0.21 & & \\
\hline Solar & 0.17 & 0.03 & \\
\hline Wind & -0.18 & -0.09 & 0.04
\end{tabular}

Table 2: Spearman rank correlation coefficients between the stations ordered by mean deviation of each weather parameter.

Table gives the correlations between the ranks of stations ordered by the median deviation of each weather parameter, i.e. between the orders of stations as they appear in Figure . As can be observed manually there are some trends (e.g. station 71 has the 
greatest negative deviation for temperature, solar and wind), but overall the coefficients confirm that there is no clear relationship between the variations in each of the weather parameters. 


\subsection{Microclimate variations in the temporal domain}

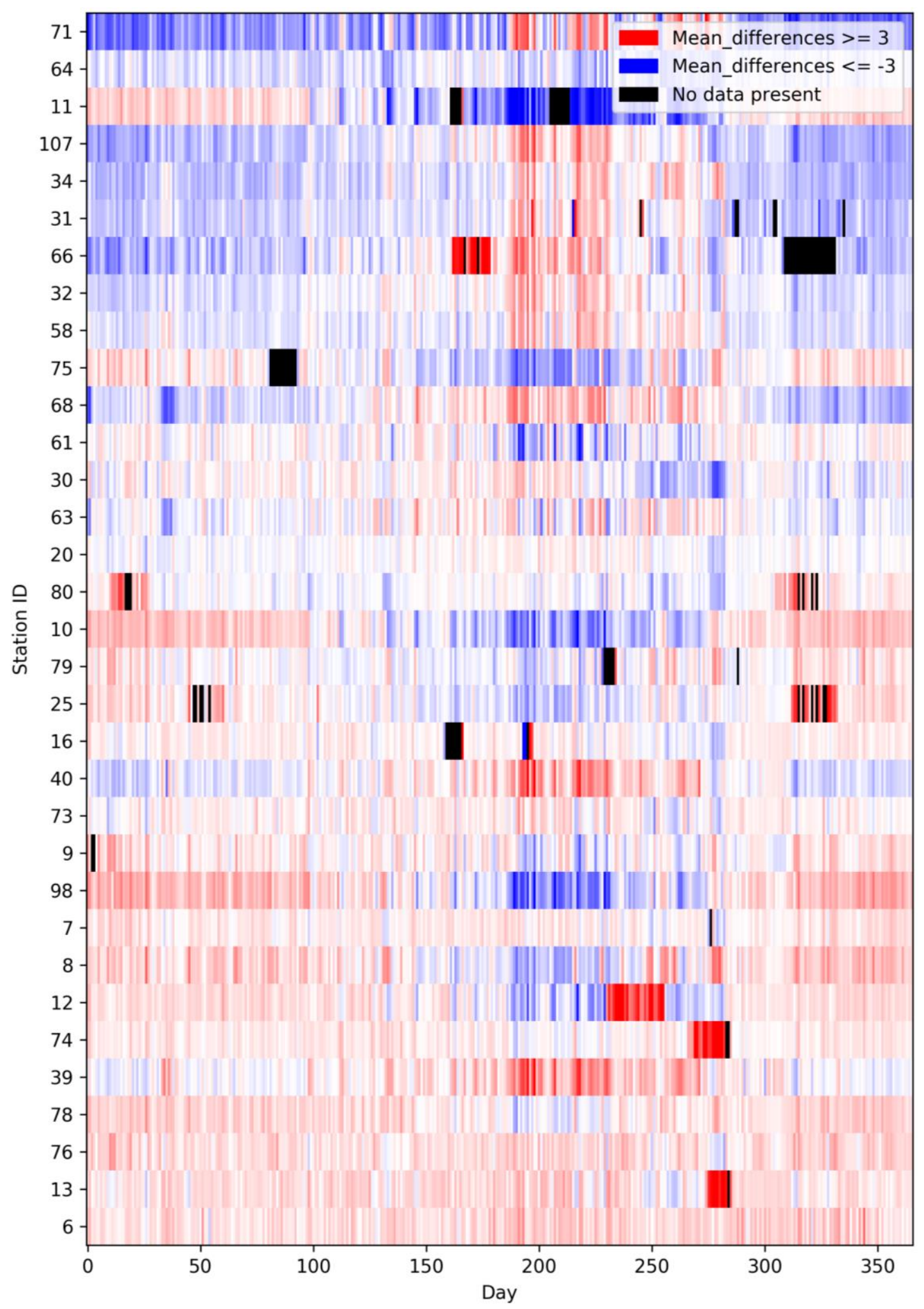

Figure 7: Heat map showing the deviation of the daily average dry bulb temperature at each station from the mean across all stations for that day, from $\leq-3$ (blue) to $\geq 3$ (red). Missing days appear black. Rows are sorted in order of the average total deviation. 
Considering the temporal domain when comparing the variation between stations allows us to examine whether there are groupings of divergence from the mean at certain times of the year, which would not be apparent in the distributions shown in the previous section. Figure shows a heat map of the divergence of the dry bulb temperature at each station from the mean across all stations, similar to the distributions examined in Figure (a). The data here has been averaged on a daily basis, for clarity of presentation. Rows are sorted by mean deviation for that station ${ }^{7}$, with 'colder' stations near the top and 'warmer' stations towards the bottom. Pale colours indicate small deviations from the mean, so rows near the middle that are largely white (e.g. station 20) are very close to the mean for the whole year.

It is notable that there are some stations (e.g. 64) that are consistently slightly below the mean, while others (e.g. 71) are dramatically colder at some times and dramatically warmer at others. The same is true for the warmer stations, though there are more that are consistently warmer; the six warmest stations have almost no colder hours. This trend is discernible in 6(a), with colder stations having somewhat larger ranges.

Looking at the distribution of the discrepancies from the mean through the year, there appears to be a bimodal seasonal trend, with some stations much colder in winter and warmer in summer, and others the opposite. This is likely due to local factors exacerbating or counteracting extreme temperatures, thus either damping the seasonal variation or enhancing it. It is notable that there are two paler stripes, a wide area from day 80 to 180 (April to June) and a narrow area around day 300 (end of October) that have surprisingly little variation across almost all stations. This implies that the mid-season climate is less

\footnotetext{
${ }^{7}$ Figure is sorted by median as this is displayed in the box plots, accounting for the slight change in order.
} 
variable, perhaps as temperatures are more moderate. Observing the range of variations that occur at a given time (column) gives an interesting perspective on the degree of variability across the region. At certain times, from days 180 to 280 (July to September) and around day 320 (end of November), the maximum and minimum deviations occur simultaneously, indicating a $6^{\circ} \mathrm{C}$ difference across the region.

Aside from the seasonal trends, there are sporadic periods of extreme variation that are short in duration and appear uncorrelated to variations at other stations. Sometimes these occur near to missing data values, indicating a possible instrumentation fault. However many such periods occur unconnected to any known issue, showing that substantial changes in local microclimate frequently occur for short periods in isolated locations. Figures of the same form were produced for relative humidity, solar gain and wind speed, and for daily maximum and minimum values. For wind speed the split between those above and below the mean is much clearer, with lots of entirely red stations and the bottom, white stations in the middle and blue stations at the top. This likely correlates with the degree of exposure of each location. There are exceptions to this however, with short periods of the opposite variation; these would probably correlate well to a change in wind direction, indicating a location that is exposed from one direction and sheltered from another. For solar gains there are many more isolated periods of values above or below the mean, often rapidly interspersed at the same station. This is further evidence of the variability due to changing cloud cover; higher resolution examination (i.e. without daily averaging) would likely increase this effect. 


\subsection{Microclimate variations in the spatial domain}
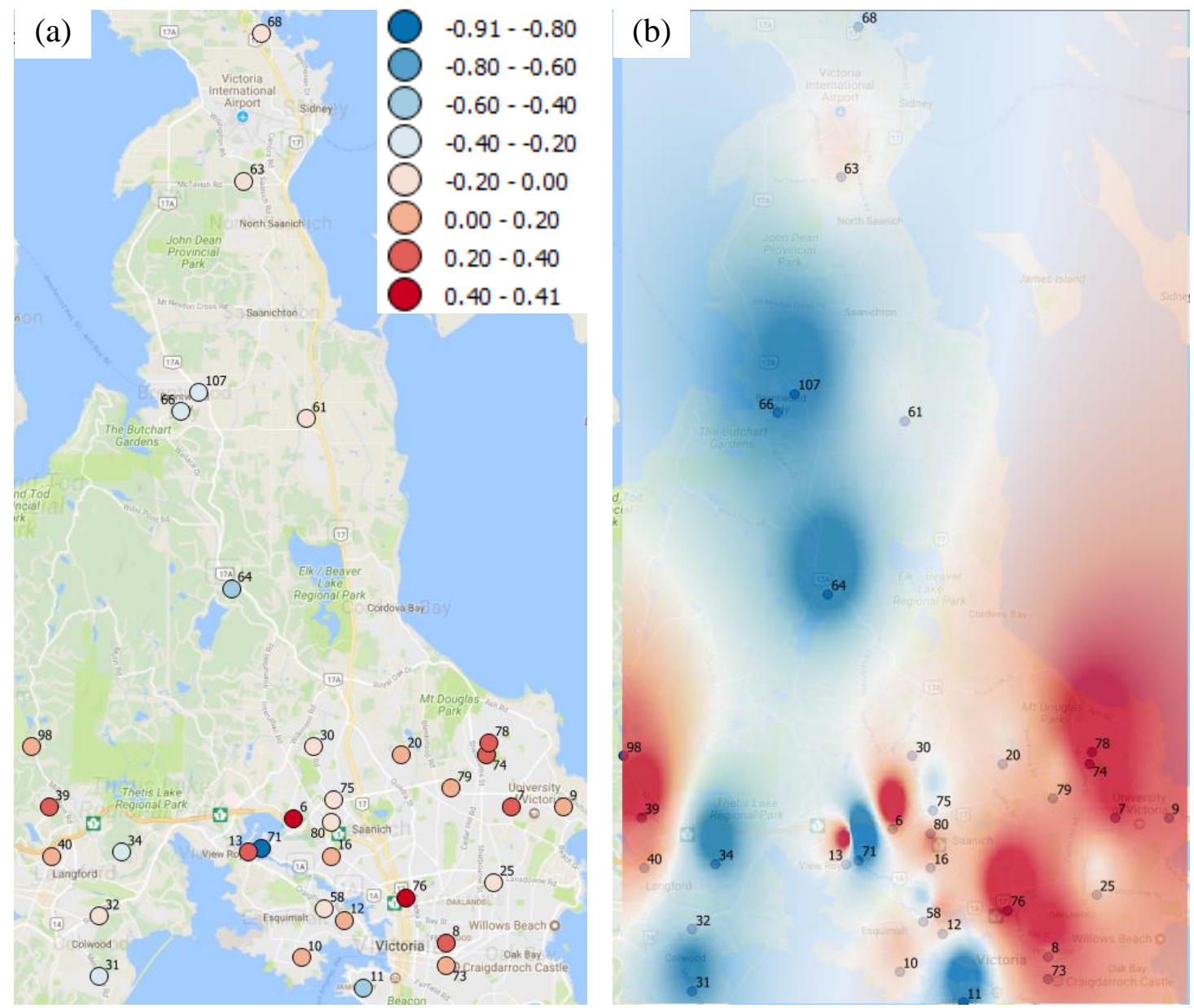

Figure 8: (a) Spatial representation of the variation in the mean deviation in temperature between stations. (b) Interpolation of mean deviation in temperature between the locations of the stations. The colour scale shows the magnitude of the mean deviation from the mean across all stations, and applies to both plots.

It would be reasonable to expect that the variation in temperature and other weather parameters would show a topographical relationship, perhaps with coastal stations having lower temperatures. Figure (a) shows the mean deviation of each station over the year from the mean over all stations, and Figure (b) interpolates this information between stations. There is no clear topographical relationship discernible in either plot. It is possible that the averaging processes is masking topographical trends that exist at certain times but which are not reflected in the overall deviation. However, it is apparent that there is no easy explanation for the overall annual variation in terms of topology. 


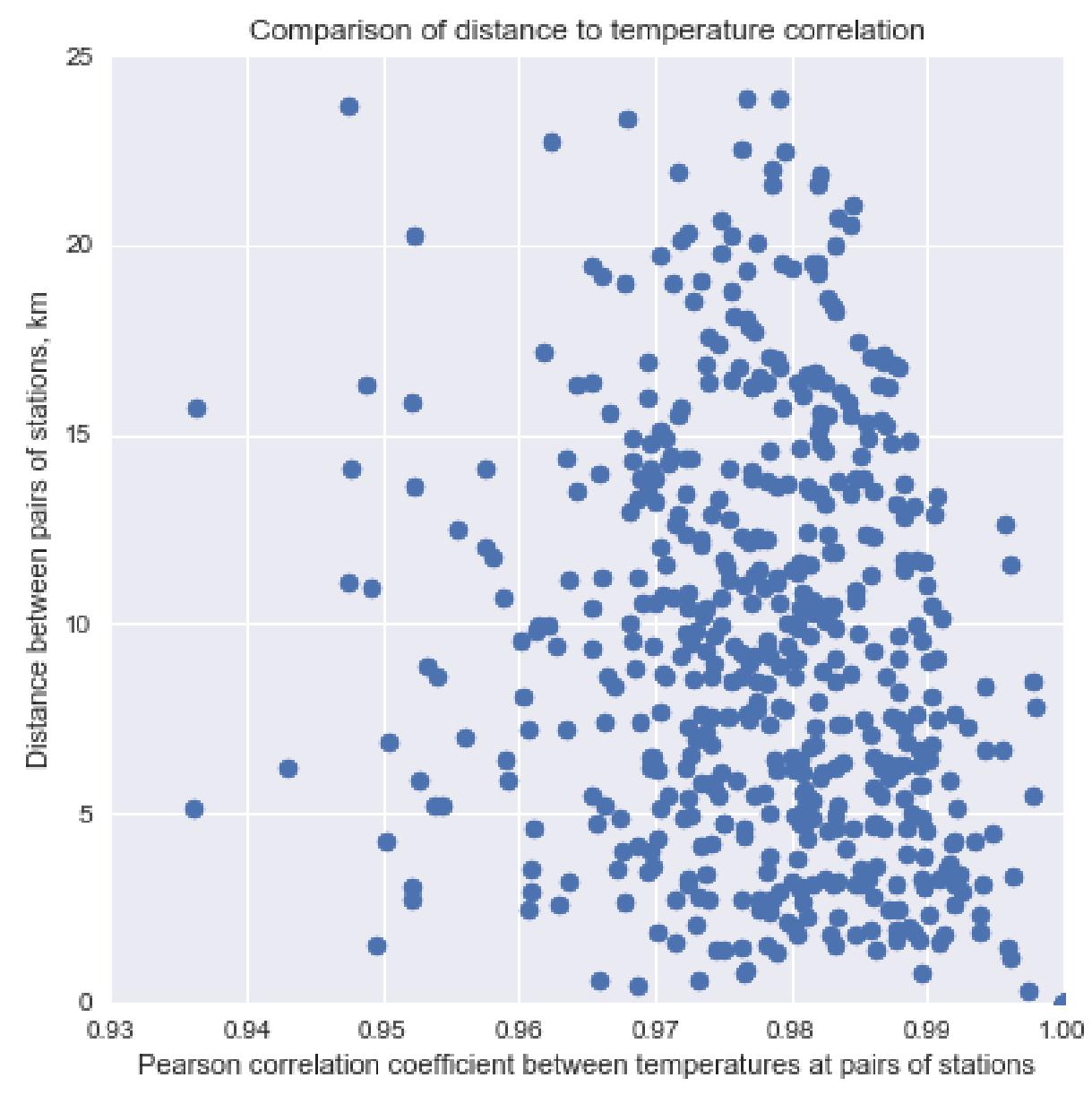

Figure 9: Comparison of distance between pairs of stations and the correlation coefficient between the temperatures at those stations.

It might be expected that the spatial distance between stations would correlate well with the similarity between the microclimate at each station at a given time, if the averaging of data above is concealing relationships that exist at different times. Figure plots the distance between the 528 possible pairs of stations against the Pearson correlation coefficient between the hourly temperature time series recorded at each station. If location was strongly correlated to climatic similarity, we would expect to see a clear inverse relationship (low distance gives high correlation, and vice versa). This is evidently not the case, suggesting that many other factors must be accounted for, a fact well-known to meteorologists but ignored by all building simulation practitioners using weather files interpolated between nearby sites. 


\section{Results and discussion of building energy use variations}

\subsection{Naturally-ventilated case}

The EnergyPlus simulations executed for all weather stations indicate that the annual heating energy use of the naturally-ventilated building varies between 6881 and 12660 $\mathrm{kWh} / \mathrm{a}$ depending on the location, with most values being reasonably normally distributed between 7000 and 9000kWh/a, as shown in the histogram in Figure (a). The heating energy use averaged over the simulation results for all stations is $8161.4 \mathrm{kWh} / \mathrm{a}$, and the heating energy use obtained by running a simulation using the mean weather data over all stations is $8161.2 \mathrm{kWh} / \mathrm{a}$, as shown by the blue line in Figure (b). The simulation using the CWEC weather file for the airport gives a heating energy use of $7991 \mathrm{kWh} / \mathrm{a}$, as shown by the green line in Figure (b).
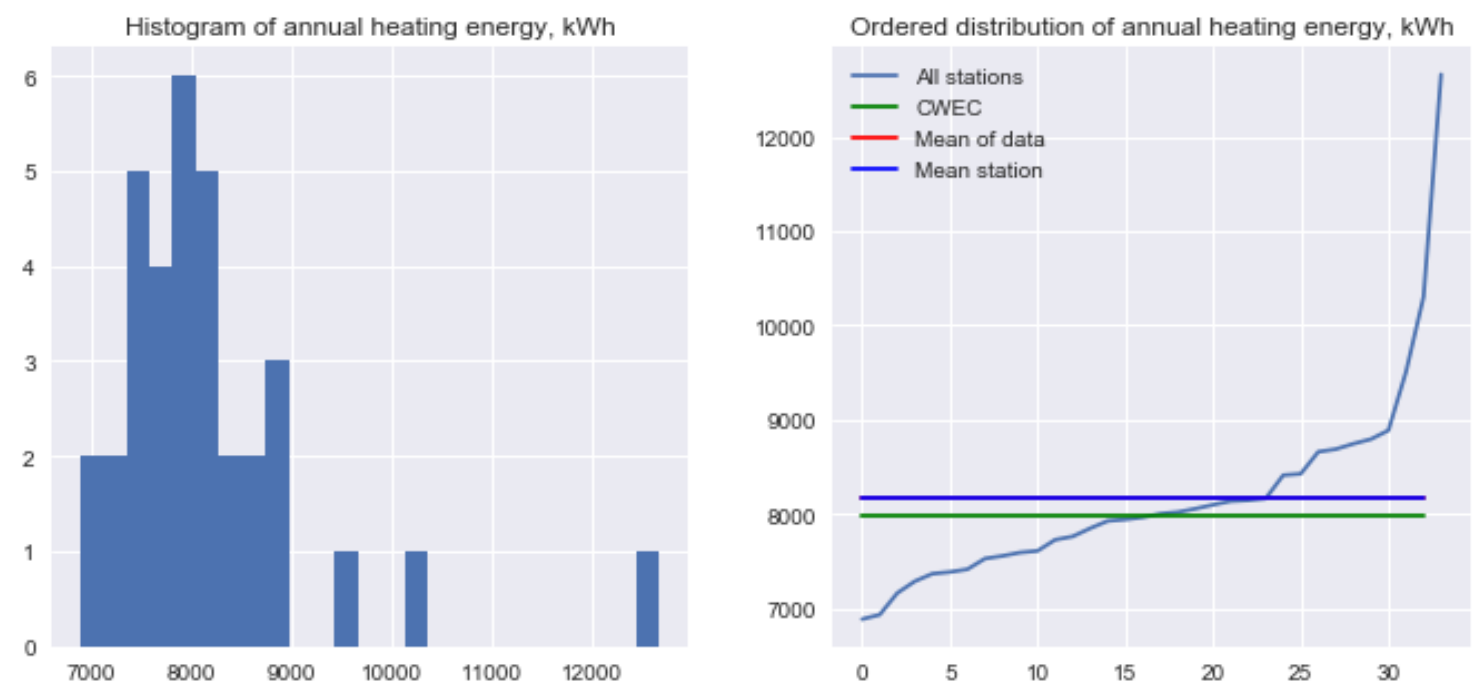

Figure 10: (a) Histogram of annual heating energy use for all stations. (b) Ordered distribution of the annual heating energy use for all stations, with the result for the CWEC weather file, the mean of all stations, and the simulation result for the mean weather data shown for comparison (the latter are coincident).

Even excluding the three stations with very high values, 30 stations give a spread of $2000 \mathrm{kWh} / \mathrm{a}$, or $+/-$ around $12 \%$ of the mean value. The interquartile range is $858 \mathrm{kWh} / \mathrm{a}$, 
so there is an average deviation of around $5 \%$ of the mean value. This is a dramatic source of error that is introduced into the simulation of building energy use due to climatic variations over a relatively small area. It is notable that the average of all simulation results and the simulation result for the average weather data give such close values, indicating that there are no dramatically nonlinear effects being introduced in the simulation, or at least that such effects are mirrored equally about the mean. Although this study does not examine the variation between years, and the CWEC weather data is not directly comparable to the single year data used, it is notable that the heating energy use from the CWEC file falls reasonably close to the mean results.
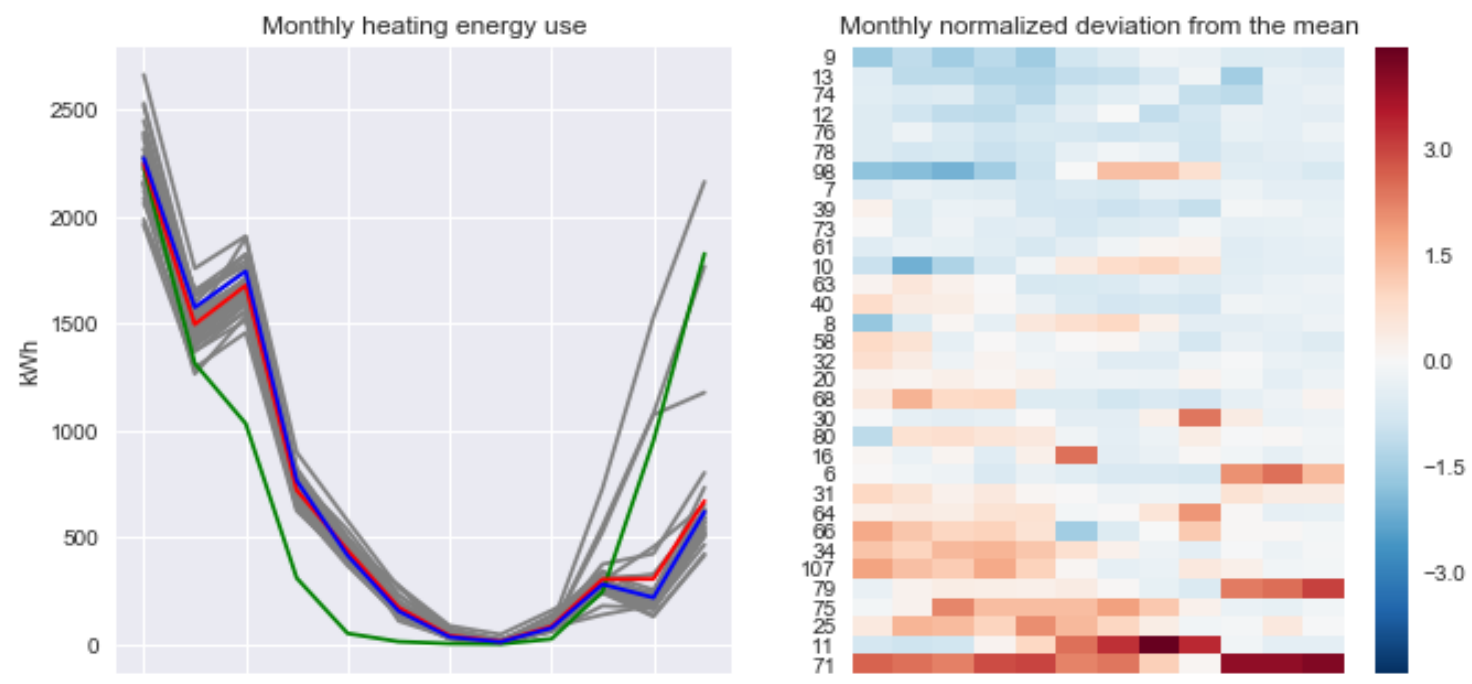

Figure 11: (a) Monthly heating energy use for all stations (grey), with the CWEC result (green), mean over all stations (red) and the simulation result for the mean weather (blue) for comparison. (b) Monthly normalised deviation from the mean of all stations.

As with any real year of weather data, there are anomalies in the 2012 data used here, as shown in the monthly heating energy use results in Figure (a): there is a particularly high heating load in March and a particularly low load in November, visible as departures from the expected seasonal profile. The mean of all results and the result for the mean weather data follow these trends, though notably the latter (blue line) does so to a less extreme 
extent, indicating that some nonlinear behaviour is captured by the simulations of extreme stations. The CWEC heating energy results, shown by the green line in Figure (a), give a much more usual seasonal profile, being much lower in the spring and higher in the autumn.

11(b) shows the discrepancy of each heating energy use value from the mean values for that month, normalized by subtracting from the monthly average and dividing by the monthly standard deviation. The plot is sorted by the total normalized deviation. It is clear that station 71 has a very high positive divergence (higher than average heating load) in all months, which fits with the temperature data examined in the previous section. Station 11 has the greatest normalised divergence overall, being well over 3 standard deviations higher than the mean in August (though because loads are lowest in August at an average of $83 \mathrm{kWh}$, the absolute discrepancy is not that large). The three extremely high heating load stations diverge dramatically from the others for the late autumn period while remaining relatively normal at other times. These appear in Figure 11(b) as the dark sections in the last three months.

It is significant that the pattern of heating energy use variation differs from that for temperature variation (Figure ) due to the low heating loads in summer months ${ }^{8}$. In general, buildings are only influenced by outside temperature between certain bounds, idealised as the base temperature in degree-day methods. Deviations in temperature that remain between those points at which heating, cooling or overheating become significant therefore do not affect the heating energy use.

\footnotetext{
${ }^{8}$ It should be noted that because Figure (b) is normalized monthly whereas Figure is not normalized, they are not directly comparable, though the presence or absence of the relevant trends can be observed in both.
} 
(a) Dry bulb temp, C

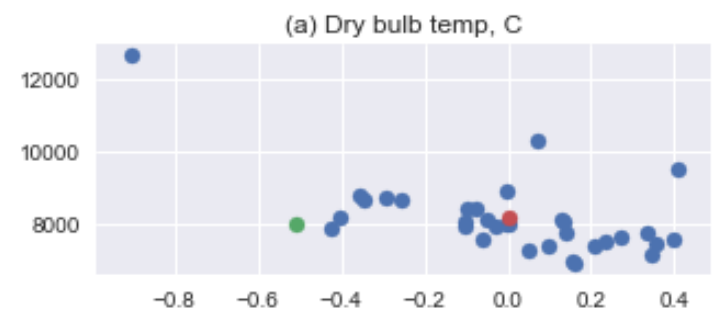

(c) Global horiz. solar, W/m2

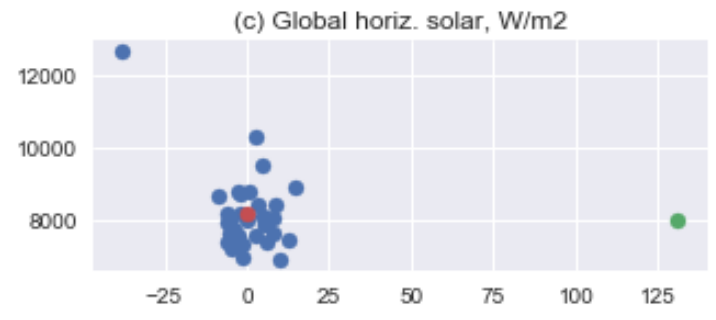

(b) Relative humidity, \%

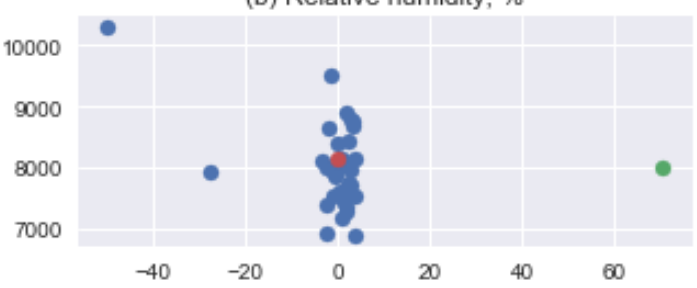

(d) Wind speed, $\mathrm{m} / \mathrm{s}$

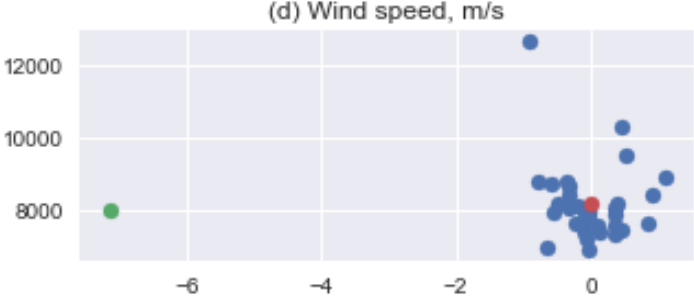

Figure 2: Comparison of total annual heating energy use (y-axes, kWh/a) and mean deviation in weather parameters from the mean of all station (x-axes, units in titles). The CWEC data is shown in green, and the energy use obtained from a simulation using the average weather data in red.

\begin{tabular}{c|c|c|c|c} 
& Temperature & RH & Solar gain & Wind speed \\
\hline Heating energy & -0.61 & -0.48 & -0.53 & -0.17
\end{tabular}

Table 3: Correlation coefficients between annual heating use and the average deviation between each weather parameter and the mean of all stations.

In terms of the other weather parameters examined in the previous section, there is no clear correlation between the deviation in these parameters and the heating energy use obtained from simulations. Figure 2 shows the average deviations from the mean value across all stations plotted against the heating energy use for that station. The CWEC values are shown in green and the simulation using average data in red (which is coincident with the average of all simulation results). It is interesting that while the CWEC results are reasonably central in terms of heating energy, there are very large divergences in all weather parameters. Temperature is the closest to the mean, which is still -0.6C away, greater than all but one station. 
The correlation coefficients between these values are given in Table. There is a moderate correlation for deviations in temperature, solar gain and relative humidity, with very weak correlation for wind speed deviation.

\subsection{Air-conditioned case}
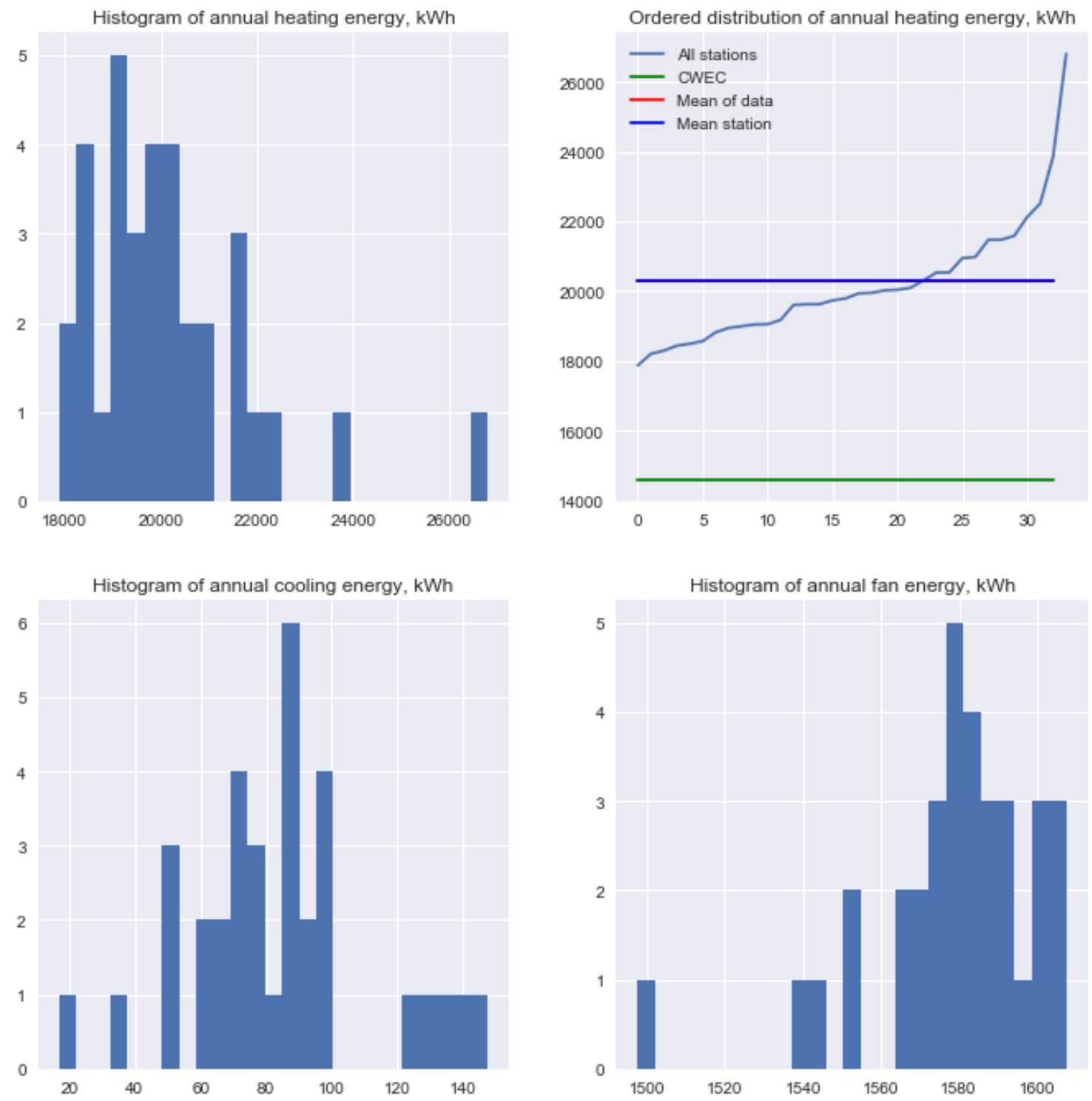

Figure 3: (a) Histogram of annual heating energy use for all stations. (b) Ordered distribution of the annual heating energy use for all stations, with the result for the CWEC weather file, the mean of all stations, and the simulation result for the mean weather data shown for comparison (the latter are coincident). (c) Histogram of annual cooling energy use for all stations. (d) Histogram of annual fan energy use for all stations. 
The heating energy results for the air-conditioned case very closely follow those of the naturally-ventilated case, as shown in Figure 3(a) and (b). This is likely because as stated in the introduction, the outdoor temperature boundary condition dominates in all buildings. The average over all station results is $20,167 \mathrm{kWh} / \mathrm{a}$, while the simulation with mean weather data gives 20,313kWh/a. Simulations range from $17,880 \mathrm{kWh} / \mathrm{a}$ to $26,799 \mathrm{kWh} / \mathrm{a}$, and the interquartile range is $1,836 \mathrm{kWh} / \mathrm{a}$ or $10 \%$ of the mean value.

The air-conditioned building differs from the naturally-ventilated case in that there is a more significant summer heating load, as shown in Figure 4(a). However, this is not present in the results for the CWEC weather file as shown in green in Figure 4(a), which predicts the annual heating energy use to be $14,595 \mathrm{kWh} / \mathrm{a}$ as shown in green in Figure 3(b).
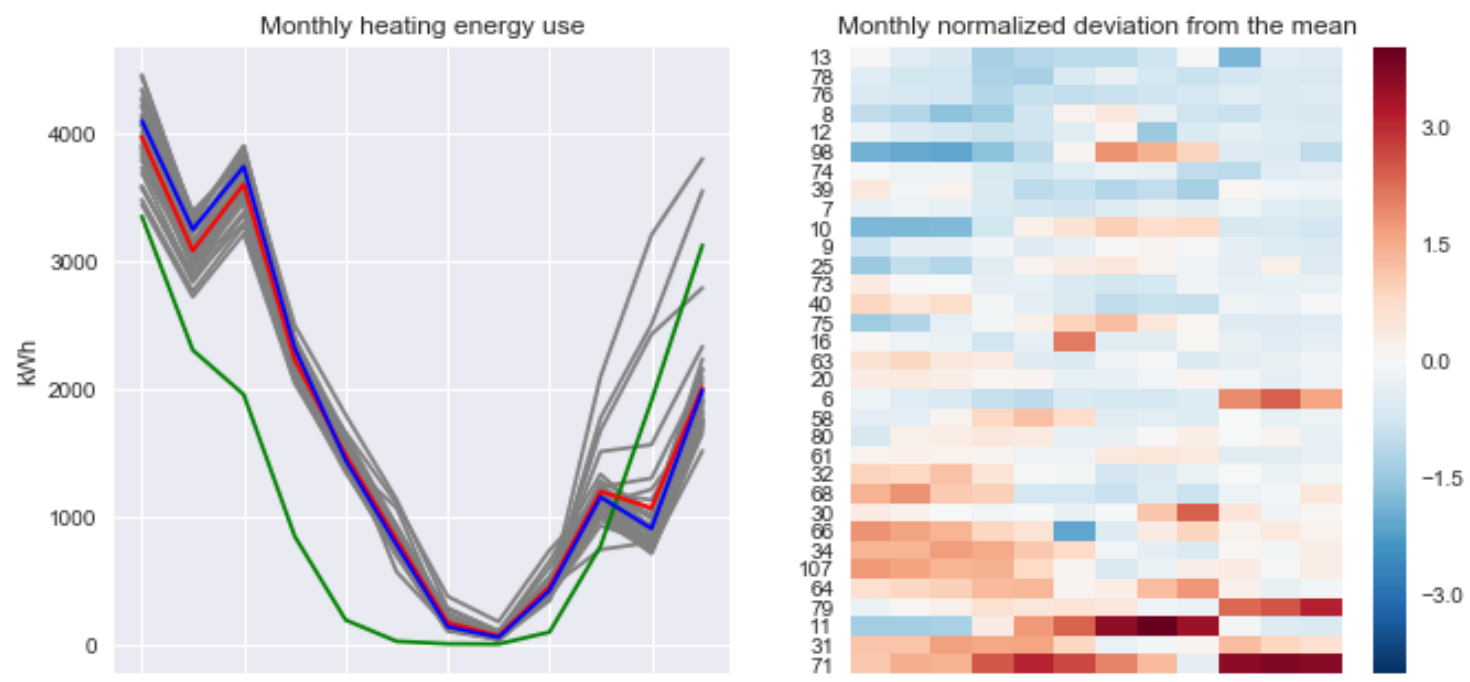

Figure 4: (a) Monthly heating energy use for all stations (grey), with the CWEC result (green), mean over all stations (red) and the simulation result for the mean weather (blue) for comparison. (b) Monthly normalised deviation from the mean of all stations.

For cooling energy the magnitude of the energy use is smaller, as Victoria is a heating dominated climate, but this leads to significant relative variations, as shown in Figure 3(c). The mean cooling energy use is $83 \mathrm{kWh} / \mathrm{a}$, but ranges from 17 to $148 \mathrm{kWh} / \mathrm{a}$. The 
interquartile $50 \%$ of solutions span $+/-15 \%$ from the mean. There is comparatively little variation in fan energy (Figure 3(d)) as this is not strongly coupled with climate.

\begin{tabular}{c|c|c|c|c} 
& Temperature & RH & Solar gain & Wind speed \\
\hline Heating & 0.67 & -0.49 & -0.61 & -0.46 \\
\hline Cooling & 0.034 & 0.035 & -0.24 & -0.37 \\
\hline Fans & 0.55 & -0.072 & 0.14 & -0.022
\end{tabular}

Table 4: Correlation coefficients between annual heating, cooling and fan energy use and the average deviation between each weather parameter and the mean of all stations.

The correlations for the air-conditioned case for heating, cooling and fan energy to the average deviations in weather parameters are shown in Table. The values for heating energy are aligned with those for the naturally-ventilated case. There is essentially no correlation between cooling energy use and temperature deviation or relative humidity, with a weak correlation to solar gain and wind speed. Fan energy is only correlated with temperature, but as noted above the variations are small.

\section{Conclusions}

Building simulation is starting to place greater emphasis on the accurate prediction of actual building behaviour and energy use, rather than the comparative analyses of the relative impact of design measures. This is in part driven by a move towards performancebased rather than reference-based building energy regulations. The margins for error also become narrower when high levels of energy performance are required, for example to meet Passive House standards. When simulation is performed for such purposes, the use of weather data from a (not very) nearby airport becomes an inexcusably great source of error.

We examine the variations in microclimate between 33 weather stations located close to 
Victoria, BC, Canada, and the impact of these variations on building energy simulation results. We find that there are differences in average annual temperature of around $+/-$ $0.5^{\circ} \mathrm{C}$, and temperature differences of up to $6^{\circ} \mathrm{C}$ across the region at certain times. There are even greater fluctuations in solar gain, likely due to transient cloud cover patterns. There is no clear topographical or spatial link between the deviations.

When specific station weather data is used for energy simulations, only $50 \%$ of stations fall within $+/-5 \%$ of the mean heating energy use; excluding outliers, there is a variation of $+/-12 \%$ of the mean heating energy use, equal to a range of $2000 \mathrm{kWh} / \mathrm{a}$ or $18 \mathrm{kWh} / \mathrm{m}^{2} / \mathrm{a}$. This holds for both a naturally-ventilated and a fully serviced building, which give very similar results. For the latter, only $50 \%$ of stations fall within $+/-15 \%$ of the mean cooling energy use, though this is smaller in magnitude.

While previous studies have examined the use of high resolution weather information, to our knowledge they have not had the benefit of closely located weather measurements giving a reliable source of microclimate data with high spatial resolution. While Demanuele et al (2011) found significant increases in overheating in going from a suburban to an urban location, much of the data was derived from two weather stations. Here we have found significant deviation in all other weather variables which has a further impact on building thermal performance.

Using a single weather file for a particular year (setting aside the issue of inter-year variations), building simulation practitioners typically makes statements that "building design $\mathrm{X}$ uses $\mathrm{Y} \mathrm{kWh} / \mathrm{a}$ of energy for heating”. This work suggests that there could significant deviation between nearby locations, meaning that a large uncertainty range would be required. Although this work examines only a single year so it is not possible 
to draw out long term comparisons, there are clear differences across the locations and therefore the use of single weather file could certainly be misleading.

While this work does not examine the impact of climatic variations on building design, it is apparent that if a building were to be designed for each location, one would likely get a significantly different answer for different locations. This would be especially true for locations which are below average for the winter and then above average in the summer., and vice versa.

\subsection{Future work}

A clear next step for future work is to examine the differences between typical weather data generated for specific locations but sampling data from multiple years. This could follow a methodology similar to the generation of Typical Meteorological Years, though 30 years of data are not available, so some adaptation will be necessary. Performing comparative analysis and simulations for all available years of data would also allow the magnitude and impact of the variations between years to be compared to those between locations.

Another profitable direction for future work is to examine the impact of the changes noted here on the optimal designs of buildings, by executing an optimization algorithm for each location separately and comparing the changes in design parameters. This would be particularly interesting where there is a specific target value to be achieved, for example number of overheating hours. An extension to this concept would be to optimize building designs that are robust to local changes in climate, by using the optimization algorithm to find designs that perform well across all locations.

As well as further exploring the impacts of the variations examined here, future research should provide solutions to the problems raised. This would ideally deliver a practical method for the generation of custom weather files for a specific location that is far more 
accurate than the current practice of interpolation. One possible approach is the use of machine learning to discern the hidden relationships between different topological and spatial factors and the resulting climatic variations. Physics based 'meso-scale' modelling could also be used to achieve this, though with significant run time penalties. 


\section{References}

Allegrini, Jonas, Viktor Dorer, and Jan Carmeliet. 2012. "Influence of the Urban Microclimate in Street Canyons on the Energy Demand for Space Cooling and Heating of Buildings." Energy and Buildings 55: 823-32.

Allegrini, Jonas, Viktor Dorer, and Jan Carmeliet. 2015. "Influence of Morphologies on the Microclimate in Urban Neighbourhoods." Journal of Wind Engineering and Industrial Aerodynamics 144: 108-17.

Bhandari, Mahabir, Som Shrestha, and Joshua New. 2012. Evaluation of Weather Datasets for Building Energy Simulation. $\quad$ Vol. 49. https://doi.org/10.1016/j.enbuild.2012.01.033.

Coley, D, and Kershaw, T, (2010). "Changes in internal temperatures within the built environment as a response to a changing climate." Building and Environment 45, 89-93.

Crawley, Drury B. 1998. “Which Weather Data Should You Use for Energy Simulations of Commercial Buildings?” Transactions-American Society of Heating Refrigerating and Air Conditioning Engineers 104: 498-515.

Demanuele, C, Mavrogianni, A, Davies, M, 2011. "Using localised weather files to assess overheating in naturally ventilated offices within London's urban heat island”. Building Services Engineering Research and Technology, 33, 351-369

Dorer, Viktor, Jonas Allegrini, Kristina Orehounig, Peter Moonen, Govinda Upadhyay, Jérôme Kämpf, and Jan Carmeliet. 2013. "Modelling the Urban Microclimate and Its Impact on the Energy Demand of Buildings and Building Clusters." Proceedings of BS 2013: 3483-89. 
Eames, Matthew, 2016 “An update of the UK's design summer years: Probabilistic design summer years for enhanced overheating risk analysis in building design." Building Services Engineering Research and Technology, 37: 503-522.

Eames M, Kershaw T, Coley D, 2012 "The appropriate spatial resolution of future weather files for building simulation”, Journal of Building Performance Simulation, 6, 347-358.

Eames, Matthew, Ramallo-Gonzalez, Alfonso, Wood, Mike. 2016, "An update of the UK's test reference year: The implications of a revised climate on building design." In Building Services Engineering Research and Technology, 37: 316-333.

Evins, Ralph, Jonas Allegrini, and Peter Moonen. 2014. "Emulating Site-Specific Wind Flow Information for Use in Building Energy Simulations." In Building Simulation and Optimization (BSO 2014), UCL, London, UK.

Gu, Lixing. 2007. “Airflow Network Modeling in EnergyPlus.” In Building Simulation. Herrera, Manuel, Natarajan, Sukumar, Coley, David, Kershaw, Tristan, RamalloGonzalez, Alfonso, Eames, Matthew, Fosas, Daniel, and Wood, Michael, 2017, “A review of current and future weather data for building simulation". In building Services Engineering Research and Technology, 38: 602-627.

Hong, Tianzhen, Wen-Kuei Chang, and Hung-Wen Lin. 2013. “A Fresh Look at Weather Impact on Peak Electricity Demand and Energy Use of Buildings Using 30-Year Actual Weather Data.” Applied Energy $111 \quad$ (November): 333-50. https://doi.org/10.1016/j.apenergy.2013.05.019.

Huang, J, 2014. "Development of 3012 IWEC2 weather files for international locations 
(RP-1477)". ASHRAE Trans, 120: 340-355

Levermore, GJ, Parkinson, JB, Laycock and PJ, Lindley, S, 2014. "The Urban Heat Island in Manchester 1996-2011”. BIn building Services Engineering Research and Technology, 36, 343-356.

Muneer, T, Gul, M, Kambezidis, H, 1997, "Solar radiation models based on metereological data". In ISES 1997 World Congress, Taejon, Korea.

Neto, A.H., Fiorelli, F.A.S.. 2008. Comparison between detailed model simulation and artificial neural network for forecasting building energy consumption. Energy and buildings, 40, 12, 2169-2176.

Numerical Logics. 1999. "Canadian Weather for Energy Calculations, Users Manual and CD-ROM.” Environment Canada, Ottawa.

Perry M, Hollis D, 2005. "The generation of monthly gridded datasets for a range of climatic variables over the United Kingdom”, International Journal of Climatology, 25 (2005), 1,041-1,054

Perez, Richard, Ineichen, Pierre, Seals, Robert, Michalsky, Joseph and Stewart, Ronald, 1990“Modeling Daylight Availability and Irradiance Components from Direct and Global Irradiance", Solar energy, 44, 271-289.

Psiloglou, B, and Kambezidis, H, 2007. "Performance of the meteorological radiation model during the solar eclipse of 29 March 2006", Atmos. Chem. Phys. 7, 60476059.

Wilcox, S and Marion, W. 2008. "User's manual for TMY3 data sets". Golden, CO: National Renewable Energy Laboratory Golden, 2008. 